\title{
Diagnostic of tautomer behaviour on QSAR models and AM1 optimisation
}

\author{
T Thalheim ${ }^{1,2^{*}}$, D Wondrousch ${ }^{1,2}$, S Stöckl ${ }^{1,2}$, D Mulliner ${ }^{1,2}$, R-U Ebert ${ }^{1}$, R Kühne ${ }^{1}$, G Schüürmann ${ }^{1,2}$ \\ From 6th German Conference on Chemoinformatics, GCC 2010 \\ Goslar, Germany. 7-9 November 2010
}

For molecules with mobile hydrogen atoms, the result of quantitative structure-activity relationships (QSARs) as well as quantum chemical geometry optimisation depends on the position of the respective hydrogen atoms. Thus to obtain reliable results, tautomerism needs to be taken into account.

With our in-house software ChemProp, we set up four different kinds of tautomerism and generated the tautomers for a random set of approximately 1000 structures included in the EINECS (European Inventory of Existing Commercial Chemical Substances) database. In total, around 20000 different tautomers were obtained.

Different QSARs, as for the prediction of the partition coefficient blood/air $\left(\mathrm{K}_{\mathrm{ba}}\right)$ or the primary biotransformation half-lives of organic chemicals in fish were applied to the subset of generated compounds. AM1 geometry optimisation is done additionally to each single structure. For each substance, the variability of the results due to the different tautomer forms has been inspected.

Finally, we come up with a suggestion of the most stable definition of tautomerism for computer supported generation. This definition includes the major cases of tautomerism and allows a suitable, fast generation of tautomers of a given input structure. Furthermore it mostly covers the extreme values of QSAR predictions for tautomeric forms of one structure.

This study has been financially supported by the EU project OSIRIS (IP, contract no. 037017), 2FUN (contract No. 036976) and the Helmholtz Impulse and Networking Fund through Helmholtz Interdisciplinary Graduate School for Environmental Research (HIGRADE).

'UFZ Department of Ecological Chemistry, Helmholtz Centre for Environmental Research, Leipzig, Germany

Full list of author information is available at the end of the article
Author details

'UFZ Department of Ecological Chemistry, Helmholtz Centre for

Environmental Research, Leipzig, Germany. ${ }^{2}$ Institute for Organic Chemistry, TU Bergakademie Freiberg, Freiberg, Germany.

Published: 19 April 2011

doi:10.1186/1758-2946-3-S1-P24

Cite this article as: Thalheim et al:: Diagnostic of tautomer behaviour on QSAR models and AM1 optimisation. Journal of Cheminformatics 20113 (Suppl 1):P24.
Publish with ChemistryCentral and every
scientist can read your work free of charge
"Open access provides opportunities to our
colleagues in other parts of the globe, by allowing
anyone to view the content free of charge."
W. Jeffery Hurst, The Hershey Company.
- available free of charge to the entire scientific community
- peer reviewed and published immediately upon acceptance
- cited in PubMed and archived on PubMed Central
- yours - you keep the copyright
Submit your manuscript here:
http://www.chemistrycentral.com/manuscript/ 